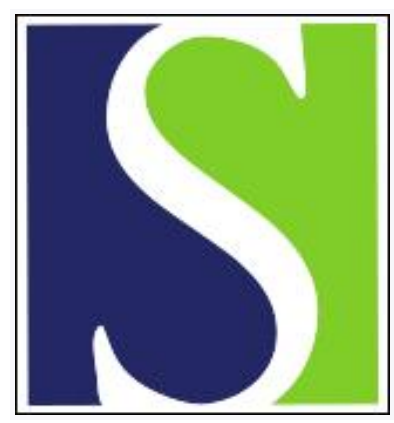

Scand J Work Environ Health 2015;41(3):259-267

https://doi.org/10.5271/sjweh.3487

Published online: 20 Feb 2015, Issue date: 01 May 2015

Primary selection into shift work and change of cardiovascular risk profile

by Yong M, Germann C, Lang S, Oberlinner C

A primary selection in favor of future shift workers is not suggested in our cohort of male professional trainees. Smokers were already more prevalent among future shift workers before the start of their career. The social environment associated with shift work is in part responsible for the development of smoking behavior which is set at the early phase of the occupational career.

Affiliation: Occupational Medical and Health Protection Department, BASF Societas Europaea, Ludwigshafen, Germany. mei.yong@basf.com

Refers to the following texts of the Journal: 1999;25(2):100-104 1999;25(2):85-99 2002;28(1):64-71 2008;34(3):206-212 1987;13(1):70-72 2010;36(2):142-149 2010;36(2):96-108 2012;38(6):590-599 2014;40(5):502-510

The following articles refer to this text: 2017;43(3):250-259; 2017;43(6):569-577

Key terms: cardiovascular disease; cardiovascular risk; cardiovascular risk profile; CVD; health behavior; healthy shift worker effect; healthy worker effect; longitudinal observation; primary selection; selection; shift work; shift worker; working time

This article in PubMed: www.ncbi.nlm.nih.gov/pubmed/25699971

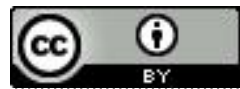




\title{
Primary selection into shift work and change of cardiovascular risk profile
} by Mei Yong, PhD, ${ }^{1}$ Christina Germann, MSc, ${ }^{1}$ Stefan Lang, PhD, ${ }^{1}$ Christoph Oberlinner, MD ${ }^{1}$

\begin{abstract}
Yong M, Germann C, Lang S, Oberlinner C. Primary selection into shift work and change of cardiovascular risk profile. Scand J Work Environ Health. 2015;41(3):259-267. doi:10.5271/sjweh.3487

Objectives A potential "healthy shift worker effect" may bias the studied effect of shift work on health. The observed differences among shift and day workers in health behavior and health outcomes can be caused by: (i) primary selection, (ii) the influence from the shift work-related environment, and (iii) the impact of shift work. We aimed to study these potential sources.
\end{abstract}

Methods A cohort of 4754 male trainees who had finished their professional training and started their career in production in a chemical company between 1995 and 2012 was identified. Among them, 1348 (28\%) were involved in rotating shift work and 3406 (72\%) in day work. Information on health behavior and risk factors for cardiovascular diseases was retrieved from the medical examinations. This information was then compared (i) at the beginning of training, (ii) at the end of training, and (iii) 3 years after the employment, in relation to the working time.

Results At the beginning of the training, the prevalence of smokers was higher among future shift workers ( $26 \%$ versus $21 \%$ ), from 1995 to 2012. During the training and the first three years of employment, a marginal decline of systolic blood pressure and an elevation of triglyceride were related with shift work. No difference was found with respect to other risk factors for cardiovascular diseases.

Conclusions Our findings do not support a primary selection in favor of shift workers. An impact of shift work on the risk profile of cardiovascular diseases was not indicated in the observation period.

Key terms cardiovascular disease; CVD; health behavior; healthy shift worker effect; healthy worker effect; longitudinal observation; shift worker; working time.

Shift work is considered to be an occupational stressor. Possible pathways from shift work to cardiovascular diseases (CVD) have been postulated through a mismatch of circadian rhythms, psychosocial disruption, unfavorable behavioral changes, and physiological stress in the biomarkers of atherosclerosis (1). Shift work was found to be related to unhealthier lifestyles such as smoking, and risk factors for CVD, including body mass index (BMI), blood pressure (BP), blood lipids, and glucose (2-4). Since these risk factors are nevertheless modifiable, it is of particular value to study the impact of shift work on these intermediates of CVD, and finally on the CVD themselves.

Meanwhile, a potential "healthy shift worker effect" resulting from selection was thought to be an intrinsic methodological limitation in epidemiological research of shift work and health. As such, healthier people are thought to be more likely to be selected or self-select into shift working time, (ie, primary selection) while unhealthier people "select out" of shift work, an ongoing selection due to differential health status (ie, secondary selection). Our previous research on the current shift working time systems provides no evidence of an adverse impact on health, either in a cross-sectional (5) or longitudinal setting (6-8). The healthy shift worker effect was one of the possible reasons for our finding. Nevertheless, the magnitude of the effect cannot be estimated in a straightforward way. Furthermore, the aforementioned risk factors for CVD, due to their wellknown predictive value, may play an important role in a primary selection at the time of professional choice.

Considering the impact of shift work on a health profile during the occupational career, the different health status could potentially occur due to (i) primary selection, (ii) the influence from the shift workrelated environment, and (iii) the impact of shift work. Unfortunately, rare existing databases can differentiate the observed differences from a number of sources. The present study aims to investigate the relationship between the future (and later the current) working time

1 Occupational Medical and Health Protection Department, BASF Societas Europaea, Ludwigshafen, Germany.

Correspondence to: Mei Yong, PhD, BASF SE, GUA / CS - H306, Ludwigshafen, Germany. [E-mail: mei.yong@basf.com] 
and the cardiovascular risk profile in a male working population involved in production: (i) at the beginning of their training, (ii) change during the three years of professional training, (iii) change during the first three years of employment after the training.

\section{Methods}

\section{Study population}

This retrospective cohort study included the trainees who started their professional training between 1991-2012 in BASF SE, a major chemical company, in Ludwigshafen, Germany. The trainees were identified based on a query of personnel records. The major professional training at BASF comprises commercial administration and technical training, with the latter comprising laboratory personnel, chemical workers, safety and protection specialist, and cooks, etc. The definition of the study population is illustrated in figure 1. Between 1991-2012, 16862 started professional skill training in the company. The choice of profession is linked with an uncertain but different degree of likelihood of being involved in shift work at the time point of employment. Until the end of 2012, 9137 were employed in the company. The status of working time is definite only once a worker joins the company after the training. During the training, the trainees were termed as "future shift workers" and "future day workers". Depending on the job types, professional training takes 2-3 years. In the present study, only the trainees of technical sections, who were likely to be involved in shift working time in the future, were included. After the training, most trainees are taken on by the mother company, BASF SE, the subsidiary companies or the contractors. Since the working time schedule has only been digitally documented since 1995 in BASF SE, the present study included the subgroup of trainees who finished the training and were taken on by the mother company because the future working time schedule would be available. To limit the potential bias due to the heterogeneity in terms of socioeconomic status, the study population was restricted to 4754 male trainees who finished the technical training and started with an activity in a production area after the training; 1348 (28\%) were assigned to rotating shift working time and $3406(72 \%)$ to the daytime working system. The analyses were then based on this eligible study population.

\section{Medical examinations at baseline and follow-up}

Figure 1 illustrates how the study population was defined and the timeframe of medical examinations at the baseline and during the follow-up. From two weeks to two months before starting their training, all trainees underwent medical examinations on a voluntary basis, including BP measurement, spirometry and a series of laboratory tests such as for total cholesterol, high density lipoprotein (HDL), triglyceride, and glucose. Screening of illegal drugs is obligatory. Blood or urine samples were taken at a random time of day, at baseline and during follow-up as well.

Body height and weight was measured so that the body mass index (BMI) could be calculated. The BMI was classified as normal $\left(<25 \mathrm{~kg} / \mathrm{m}^{2}\right)$, overweight $(25$ $\left.29 \mathrm{~kg} / \mathrm{m}^{2}\right)$, or obese $\left(\geq 30 \mathrm{~kg} / \mathrm{m}^{2}\right)$. Systolic BP values $>130 \mathrm{mmHg}$ or diastolic $\mathrm{BP}>85 \mathrm{mmHg}$ were considered elevated. Non-fasting blood samples were drawn. Triglyceride values $>150 \mathrm{mg} / \mathrm{dl}$ or total cholesterol $>180$ $\mathrm{mg} / \mathrm{dl}$ were considered as lipid metabolic risks. Serum glucose was dichotomized by $100 \mathrm{mg} / \mathrm{dl}$ to be considered as exceeding the tolerance limit.

After the end of training (ie, before assignment to a workplace) all trainees should have completed the medical examination once again. Depending on the requirements of the job activity, the employees are obliged to undergo the medical examinations regularly during professional life, on average every $2-3$ years.

\section{General characteristics and health behavior}

Information on health behavior was obtained from a medical information system in the Department of Occupational Medicine and Health Protection at BASF in Ludwigshafen. Employees self-reported the amount of drinks consumed per week and their smoking behavior. According to their smoking behavior, they were then classified into non-smokers (NS), former smokers (FS), and current smokers (CS). Alcohol drinking behavior was classified using the median amount of drinks per week: slight drinkers $(<2$ drinks/week) and moderate drinkers ( $\geq 2$ drinks/week).

\section{Shift working time system}

The two forms of fast forward-rotating 12-hour shift working schedules running at BASF Ludwigshafen's site have been described in detail in our previous publication (8), referred to as the $3 \times 12$ or $4 \times 12$ systems. In the $3 \times 12$ system with a sequence of shifts (day-night-off), a 12-hour day shift from 6:00-18:00 hours is followed 24 hours later by a 18:00-06:00-hour night shift. After a day off the employee returns to the day shift. In 1992, the so called $4 \times 12$ shift schedule, was introduced to replace the former $3 \times 12$ shift system from time to time and has been getting to be dominantly employed. The $4 \times 12$ schedule with a sequence of shifts (day-night-off-off) begins with a day shift (6:00-18:00 hours), followed 24 hours later by a night shift (18:00-06:00 hours). After two days off, 


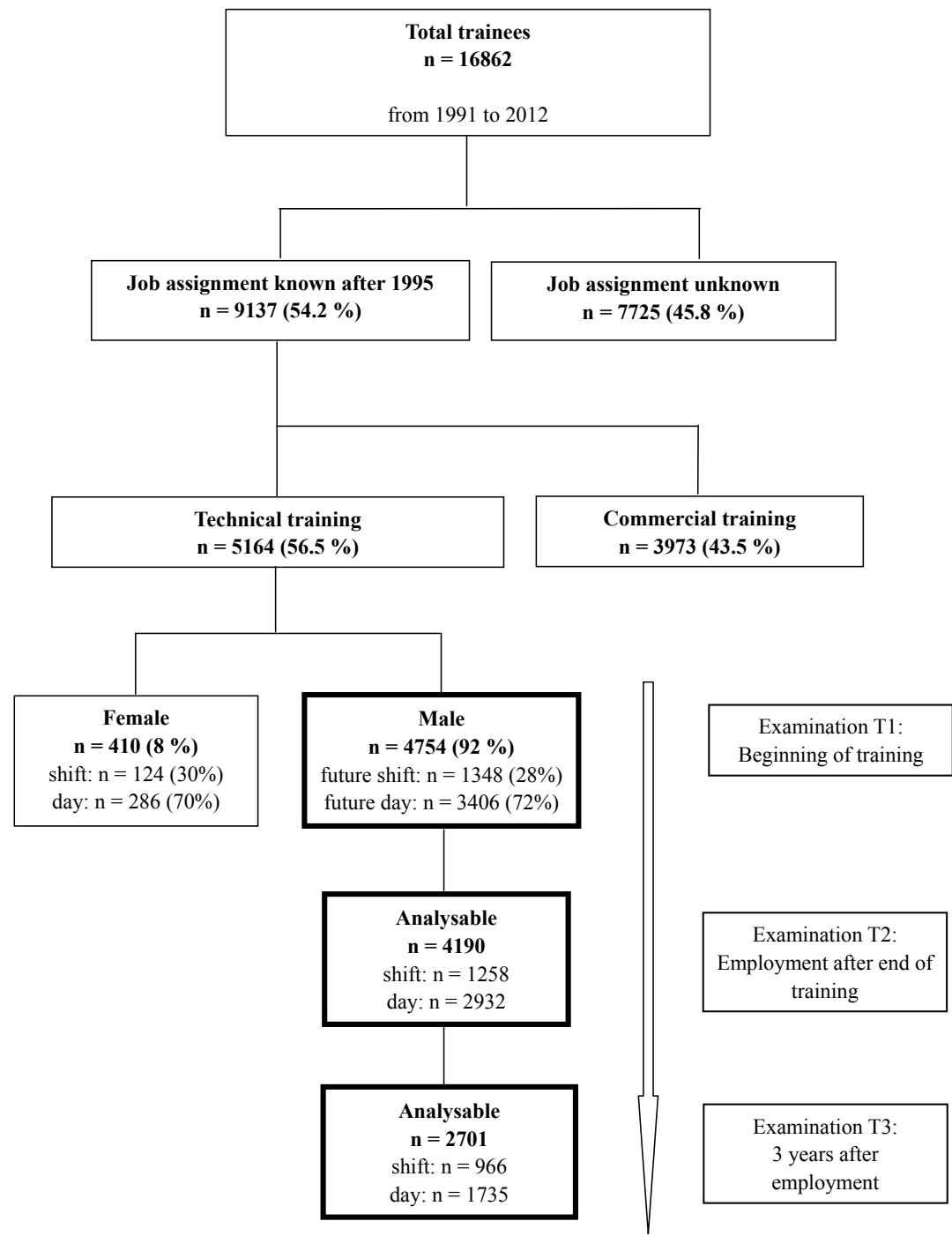

Figure 1. Time and exposure scheme of the study population. the employees returned to the next day shift. The shift schedules differ only by a resting period of one or two days after the night shift. The number of sequential night shifts is never more than one in both systems. Possible differences between these two shift schedules are not the subject of the present study. Nevertheless, a previous evaluation did not suggest a difference between these two shift systems regarding their impact on subjective health status measured by the Work Ability Index (5).

\section{Statistical analysis}

In the univariate analyses, demographic, health behavior, and metabolic factors are presented in frequencies (relative frequencies) or mean (standard deviation) according to the future working time systems. The P-values are derived by means of the Chi-square tests in the comparison of frequencies or Wilcoxon U-tests in the comparison of mean values.
Intra-individual changes in terms of body weight, BMI, drinks per week, BP, blood lipids, and glucose were then derived respectively from the medical examinations (i) at the beginning of the training, (ii) at the end of the training, and (iii) three years after the employment. With respect to the intra-individual changes, linear regression models were used to estimate the effect of shift work, with adjustment for the respective measures and age at baseline, and the time interval between the examinations.

To estimate the impact of the working time systems on the development of smoking behavior, the method of state transition was considered. Four types of behavior change were then summarized: (i) current smoker quit smoking and transitioned to a former smoker, ie, CS to FS, (ii) current smoker kept smoking, ie, CS to CS, (iii) non-smoker or former smoker became a smoker, ie, NS/ FS to CS, and (iv) non-smoker or former smoker status remained unchanged, ie, NS/FS to NS/FS. Multinomial logistic regression for categorical data was used to esti- 
mate the impact of shift work, taking type four as the reference. The working time system, which is the factor of our research interest, was forced to stay in the model regardless of its statistical significance level.

Attrition was defined to be loss to follow-up examinations for any reasons, either lack of interest, missing of laboratory parameters, leaving the company or inability to commit time. Attrition rate was studied and binary logistic regression analyses were used to investigate the risk factors for attrition at time points of employment (T2) and 3 years after the employment (T3), respectively.

All analyses were performed with SAS version 9.3 (SAS Institute, Cary, North Carolina, USA).

\section{Results}

General characteristics of the study population and lifestyles, and metabolic risk factors at the beginning of the training are presented in table 1 . The mean age of the trainees for future day or shift work was well comparable, despite the statistical significance.

The prevalence of active smoking has declined generally during the observational period. However, the relationship changed during the time. The prevalence of current smokers at the beginning of training was significantly higher among future shift workers $(30 \%$ versus $21 \%$ ) before 2002, while it showed no difference (19\% versus $22 \%$ ) after 2002 . The distribution of BMI was comparable between the groups. About $75 \%$ of each group was classified to be under- to normal weight. Fourteen per cent of each group reported to have more than two alcoholic drinks per week. No differences in terms of BP, parameters of blood lipids, and glucose were found between the groups.

In table 2 the estimates are presented for the association between the change patterns of smoking behavior and the (future) working time systems, unadjusted and adjusted for the baseline smoking status. During the time period of training, the future shift workers were more likely to switch from non- or former smokers to current smokers [odds ratio (OR) 1.22, 95\% confidence interval $(95 \% \mathrm{CI}) 1.01-1.49]$ and to remain as smokers (OR 1.34, 95\% CI 1.13-1.59) with adjustments for the time period of starting the training and age at the baseline. In model 2, the estimate for remaining as current smokers changed to below reference, after additional adjustment for the smoking status at the beginning of training. During the first three years of employment, the shift workers were more likely to keep their smoking behavior, either unadjusted or adjusted for the smoking status at the beginning of employment.

Table 3 presents the intra-individual changes with respect to metabolic risk factors of CVD during the period of training. Greater weight gain and an increase in alcoholic drinks per week was found in the group of future day workers, while the difference was no longer significant after the adjustment for the baseline measures, age, and time interval between the examinations. Decreased systolic BP and an elevation of triglyceride among the future shift workers was observed, even after the adjustment. When comparing the groups, no other noticeable changes were observed during the period of training.

The intra-individual changes during the first three years of employment after the training were presented in table 4. Again, systolic BP continued to decrease marginally and a further elevation of triglyceride among the future shift workers was observed, even after the adjustment.

Respectively at the employment (T2) and 3 years after the employment (T3), 90 (7\%) and $382(28 \%)$ of the future shift workers, and $474(14 \%)$ and $1671(49 \%)$ of the future day workers were lacking of examinations. Logistic regression analysis yielded that active smoking (OR 1.24, 95\% CI 1.18-1.30) and drinking alcohol $\geq 2$ drinks/week (OR 1.66, 95\% CI 1.12-2.45) at the beginning of training were more likely for attrition at the employment. No statistically significant association was found between characteristics and risk factors at baseline and attrition three years after the employment.

\section{Discussion}

The findings from this cohort study do not support a primary selection in favor of shift workers in the studied population. Smoking status at the beginning of training was related to future working time. The prevalence of active smoking decreased over time among the future shift workers while this did not change noticeably among the future day workers. No differences in terms of other risk factors for cardiovascular diseases were found.

The decreased prevalence of active smoking in the past decade among the trainees is in accordance with the global trend of reduced tobacco use. Almost all studies found a link between shift work and smoking status (9-13), regardless of gender and occupational fields. The Million Women Study entails a range of occupational groups; smoking women were more prevalent in shift work and shift work is more prevalent in lower socioeconomic status (9). A higher prevalence of current smoking (59\% versus $48 \%$ ) was observed among shift workers with an average age of 24 years (10), at a noticeably higher level than the prevalence from the present study (26\% versus $21 \%$ ). The Danish study including the trainee nurses (11) was the only study that investigated the primary selection into shift work and compared the cardiovascular risk factors among the future nurses prior to the start of their career and 
Table 1. General characteristics, health behavior, and metabolic risk factors among the 4754 male trainees at the beginning of their training according to future working time system. [SD=standard deviation; BP=blood pressure; HDL=high density lipoprotein; BMI=body mass index]

\begin{tabular}{|c|c|c|c|c|c|c|c|c|c|}
\hline & \multicolumn{4}{|c|}{ Shift $[N=1348(28 \%)]$} & \multicolumn{4}{|c|}{ Day $[N=3406(72 \%)]$} & \multirow[t]{2}{*}{ P-values } \\
\hline & Mean & SD & $\mathrm{N}$ & $\%$ & Mean & SD & $\mathrm{N}$ & $\%$ & \\
\hline Age at start (years) & 17.5 & 1.7 & & & 17.3 & 1.4 & & & $<0.001$ \\
\hline Body weight (kg) & 71.3 & 13.6 & & & 71.7 & 14.1 & & & 0.31 \\
\hline Systolic BP $\geq 130$ mmHg & 519 & 39 & & & 1156 & 34 & & & 0.28 \\
\hline Diastolic BP $\geq 85 \mathrm{mmHg}$ & 221 & 16 & & & 533 & 16 & & & 0.09 \\
\hline Total cholesterol $\geq 180 \mathrm{mg} / \mathrm{dl}$ & 354 & 26 & & & 831 & 24 & & & 0.44 \\
\hline Triglyceride $\geq 150 \mathrm{mg} / \mathrm{dl}$ & 291 & 22 & & & 596 & 17 & & & 0.17 \\
\hline $\mathrm{HDL}<40 \mathrm{mg} / \mathrm{dl}$ & 158 & 12 & & & 286 & 8 & & & 0.13 \\
\hline Glucose $\geq 100 \mathrm{mg} / \mathrm{dl}$ & 400 & 30 & & & 1047 & 31 & & & 0.29 \\
\hline \multicolumn{10}{|l|}{ Smoking status } \\
\hline Entry before 2002 & & & 844 & & & & 2599 & & $<0.0001$ \\
\hline Current smoker & & & 257 & 30 & & & 554 & 21 & \\
\hline Former smoker & & & 22 & 3 & & & 48 & 2 & \\
\hline Never smoker & & & 541 & 64 & & & 1926 & 74 & \\
\hline Not available & & & 29 & 3 & & & 71 & 3 & \\
\hline Entry after 2002 & & & 504 & & & & 807 & & 0.14 \\
\hline Current smoker & & & 98 & 19 & & & 177 & 22 & \\
\hline Former smoker & & & 12 & 2 & & & 14 & 2 & \\
\hline Never smoker & & & 333 & 66 & & & 491 & 61 & \\
\hline Not available & & & 61 & 12 & & & 125 & 15 & \\
\hline BMI $\left(\mathrm{kg} / \mathrm{m}^{2}\right)$ & & & & & & & & & 0.76 \\
\hline$<25$ & & & 1025 & 76 & & & 2555 & 75 & \\
\hline $25-29$ & & & 242 & 18 & & & 595 & 17 & \\
\hline$\geq 30$ & & & 75 & 6 & & & 206 & 6 & \\
\hline Alcoholic drinks $\geq 2 /$ week & & & 187 & 14 & & & 463 & 14 & 0.89 \\
\hline
\end{tabular}

Table 2. Intra-individual changes of smoking status among the 4754 male trainees according to the time period and their future working time system and the risk estimates of the respective change patterns of shift workers comparing to day workers. [NS=non-smoker; $\mathrm{FS}=$ former smoker; $\mathrm{CS}=$ current smoker; $\mathrm{OR}=0 \mathrm{dds}$ ratio; $95 \% \mathrm{Cl}=95 \%$ confidence interval; $\mathrm{NA}=$ not available]

\begin{tabular}{|c|c|c|c|c|c|c|c|c|}
\hline \multirow[b]{3}{*}{$\mathrm{T} 1 \rightarrow \mathrm{T} 2$} & \multicolumn{2}{|c|}{ Shift $N=1348$} & \multicolumn{2}{|c|}{ Day $N=3406$} & \multicolumn{2}{|c|}{ Model $1^{\text {a }}$} & \multicolumn{2}{|c|}{ Model $2^{b}$} \\
\hline & $\mathrm{N}$ & $\%$ & $\mathrm{~N}$ & $\%$ & $\mathrm{OR}$ & $95 \% \mathrm{Cl}$ & $\mathrm{OR}$ & $95 \% \mathrm{Cl}$ \\
\hline & & & & & & & & \\
\hline$N S / F S \rightarrow N S / F S$ & 646 & 48 & 1687 & 49 & 1.0 & & 1.0 & \\
\hline NS / FS $\rightarrow$ CS & 191 & 14 & 481 & 14 & 1.22 & $1.01-1.49$ & 1.21 & $0.99-1.47$ \\
\hline $\mathrm{CS} \rightarrow \mathrm{CS}$ & 288 & 21 & 553 & 16 & 1.34 & $1.13-1.59$ & 0.96 & $0.77-1.20$ \\
\hline $\mathrm{CS} \rightarrow \mathrm{FS}$ & 24 & 2 & 53 & 2 & 1.19 & $0.72-1.96$ & 0.83 & $0.49-1.39$ \\
\hline$N A$ & 199 & 15 & 632 & 19 & 0.79 & $0.65-0.95$ & 0.52 & $0.40-0.67$ \\
\hline \multicolumn{9}{|l|}{$\mathrm{T} 2 \rightarrow \mathrm{T} 3$} \\
\hline $\mathrm{NS} / \mathrm{FS} \rightarrow \mathrm{NS} / \mathrm{FS}$ & 477 & 35 & 955 & 28 & 1.0 & & 1.0 & \\
\hline NS / FS $\rightarrow$ CS & 245 & 18 & 564 & 17 & 1.03 & $0.85-1.25$ & 0.94 & $0.77-1.14$ \\
\hline $\mathrm{CS} \rightarrow \mathrm{CS}$ & 208 & 15 & 272 & 8 & 1.61 & $1.29-1.99$ & 1.41 & $1.13-1.76$ \\
\hline $\mathrm{CS} \rightarrow \mathrm{FS}$ & 10 & 1 & 33 & 1 & 0.64 & $0.31-1.34$ & 0.53 & $0.25-1.10$ \\
\hline NA & 408 & 30 & 1582 & 46 & 0.60 & $0.51-0.72$ & 0.51 & $0.43-0.61$ \\
\hline
\end{tabular}

${ }^{\mathrm{a}} \mathrm{OR}$ adjusted for time of starting the training and age at the baseline.

느odel 1 with additional adjustment for smoking status at baseline, respectively at $\mathrm{T} 1$ or $\mathrm{T} 2$.

provided the unexpected finding that the prevalence of active smoking is higher among the women who are involved in the shift work in the future. Our results are in line with that of the Danish study that smoking should be treated as a confounder, while our study population comprises male career starters in a chemical company.

Furthermore, we studied the impact of shift workrelated social environments and shift work itself on cardiovascular risk profiles. During the training, pro- vided that the initial disparity of smoking status is present, the future shift workers were more likely to take up smoking and the current smokers to continue their smoking behavior. However, after the adjustment for the heterogeneous smoking status at the baseline, the effect was diminished. Few studies reported a change in smoking behavior in a longitudinal setting $(11,14)$. Their inability to find a change in smoking behavior in the Swedish study (14) might be mostly attributed to the 
Table 3. Intra-individual quantitative changes of cardiovascular risk factors during the period of professional training among the male trainees. [SD=standard deviation; $95 \% \mathrm{Cl}=95 \%$ confidence interval]

\begin{tabular}{|c|c|c|c|c|c|c|c|c|}
\hline & \multicolumn{2}{|c|}{ Shift $(N=1348)$} & \multicolumn{2}{|c|}{ Day $(\mathrm{N}=3406)$} & \multirow[t]{2}{*}{ P-value ${ }^{a}$} & \multirow[t]{2}{*}{ Estimates $^{b}$} & \multirow[t]{2}{*}{$95 \% \mathrm{Cl}$} & \multirow[t]{2}{*}{ P-value } \\
\hline & Mean & SD & Mean & SD & & & & \\
\hline Weight $(\mathrm{kg})$ & 2.24 & 5.34 & 2.89 & 6.34 & 0.0007 & -0.10 & $-0.49-0.29$ & 0.61 \\
\hline Body mass index & 0.70 & 1.80 & 0.66 & 1.89 & 0.56 & 0.013 & $-0.10-0.13$ & 0.83 \\
\hline Drinks / week & 0.3 & 1.2 & 0.4 & 1.3 & 0.01 & 0.02 & $-0.07-0.11$ & 0.68 \\
\hline Systolic blood pressure $(\mathrm{mmHg})$ & -0.11 & 7.96 & 0.01 & 4.4 & 0.86 & -0.74 & $-1.34--0.14$ & 0.01 \\
\hline Diastolic blood pressure $(\mathrm{mmHg})$ & 0.03 & 5.2 & 0.0 & 3.0 & 0.63 & -0.23 & $-0.60-0.14$ & 0.23 \\
\hline Triglyceride & -0.11 & 3.2 & 0.2 & 8.9 & 0.08 & 3.46 & $0.95-5.96$ & 0.007 \\
\hline Total cholesterol & 0.15 & 5.29 & 0.15 & 4.5 & 0.56 & 0.10 & $-0.69-0.90$ & 0.80 \\
\hline High density lipoprotein & -0.02 & 0.66 & 0.01 & 0.55 & 0.03 & 0.04 & $-0.16-0.23$ & 0.72 \\
\hline Glucose & -2.35 & 10.8 & -2.4 & 10.3 & 0.30 & 0.27 & $-0.55-1.10$ & 0.52 \\
\hline
\end{tabular}

a Wilcoxon U-tests were used.

${ }^{b}$ Estimates from linear regression, adjusted for the measures and age at baseline and the time interval between the examinations.

Table 4. Intra-individual changes of cardiovascular risk factors during the first 3 years of employment after the training among the male trainees. [SD=standard deviation; $95 \% \mathrm{Cl}=95 \%$ confidence interval]

\begin{tabular}{|c|c|c|c|c|c|c|c|c|}
\hline & \multicolumn{2}{|c|}{ Shift $(N=1348)$} & \multicolumn{2}{|c|}{ Day $(\mathrm{N}=3406)$} & \multirow[t]{2}{*}{$P$-value a } & \multirow[t]{2}{*}{ Estimates ${ }^{b}$} & \multirow[t]{2}{*}{$95 \% \mathrm{Cl}$} & \multirow[t]{2}{*}{ P-value } \\
\hline & Mean & SD & Mean & SD & & & & \\
\hline Weight (kg) & 2.2 & 5.1 & 2.1 & 5.8 & 0.63 & 0.27 & $-0.12-0.65$ & 0.17 \\
\hline Body mass index & 0.47 & 1.50 & 0.47 & 1.75 & 0.77 & 0.01 & $-0.10-0.13$ & 0.83 \\
\hline Drinks / week & 0.26 & 1.24 & 0.25 & 1.36 & 0.36 & -0.012 & $-0.11-0.08$ & 0.80 \\
\hline Systolic blood pressure (mmHg) & -0.35 & 7.8 & 0.47 & 6.7 & 0.04 & -0.85 & $-1.45--0.25$ & 0.005 \\
\hline Diastolic blood pressure (mmHg) & -0.11 & 4.7 & 0.13 & 4.7 & 0.61 & -0.22 & $-0.60-0.15$ & 0.24 \\
\hline Triglyceride & 3.6 & 28.8 & 0.25 & 34.6 & 0.0008 & 3.65 & $1.13-6.16$ & 0.005 \\
\hline Total cholesterol & 0.60 & 10.4 & 0.84 & 10.9 & 0.54 & 0.15 & $-0.64-0.95$ & 0.71 \\
\hline High density lipoprotein & -0.012 & 2.1 & -0.06 & 2.5 & 0.29 & 0.03 & $-0.16-0.22$ & 0.78 \\
\hline Glucose & -1.27 & 11.0 & -1.44 & 10.7 & 0.86 & 0.37 & $-0.44-1.17$ & 0.37 \\
\hline
\end{tabular}

a Wilcoxon U-tests were used.

${ }^{\mathrm{b}}$ Estimates from linear regression, adjusted for the measures and age at baseline and the time interval between the examinations.

limited number of subjects (13 day and 12 shift workers) included in the study. Our finding supports that of the Dutch study (11) that smoking could be more than a confounding factor. We found that $14 \%$ in both the future day and shift workers took up smoking during the time period of training. Personal income that can be spent under one's own control is a possible reason for this change. During the training, shift work itself could not exercise any influence on health behavior, because the trainees were not involved in the process of circadian disruption. A plausible explanation for this finding is an influence from the work-related social circumstances, eg, smoking behavior of the supervisors or communal breaks during which a cigarette smoking with each other may probably act as a kind of collective pressure and promote this development. Noticeably, an additional $18 \%$ and $17 \%$ of shift and day workers respectively took up smoking during the first three years of employment, though without statistical significance for shift effect. This finding that the development of smoking behavior began and was set rather at the early phase of the occupational career would imply that more endeavors are necessary to encourage and help the career starters quit smoking, both for the shift and day workers.

Body weight and BMI at baseline and weight gain were not associated with working time in the present study. While other studies reported a positive relationship between BMI and the duration of shift work (10, 15-20). Kubo and coworkers (10) studied weight gain in an industry-based cohort study with a follow-up of up to 27.5 years, with an average age of 24 years at the first check. The effect of shift work on weight gain (obesity) was apparent after ten years of follow-up. The strength of this study is that the employees underwent medical examinations regularly so that the finding is of less concern of attrition bias. In line with our findings, the baseline body weight and BMI were comparable between the shift and day workers.

In contrast, Almelsvoort and coworkers (13) found that BMI significantly decreased accompanied by a significantly increased percentage of energy intake from fat among the shift workers during one year. The authors explained their finding to be the result of regression to the mean, on the one hand, and the confounding effect of smoking, on the other hand. The interaction between the multiple actors seems to be more complex. 
Apart from the different characteristics of shift systems and dietary culture, the Japanese studies had a much longer observational period for an underlying effect. A question could be how long a shift worker needs to gain more weight than his day-working peer. It is of considerable importance to determine the duration of shift work to induce a potential adverse effect. The benchmark dose (BMD) is a useful approach to estimate an explicit risk level using information from the entire dose-response curve (21-23). The investigators found that BMD levels for duration of shift work in workers aged 40 ranged from $21-28$ years for various degrees varying from $5-15 \%$ of relative increases in total cholesterol (21). Analogously, benchmark duration of $\geq 17.8$ years for a shift worker aged 50 years for an increase of $15 \% \mathrm{HbAlc}$ was estimated (22). In addition, BMD for weight gain of $5 \%$ and $10 \%$ relative increases was estimated between 19-23 years for a shift worker aged 40 years (23). These findings provided very useful knowledge that the progression of the cardiovascular risk profile is a long-term process. In addition, ethnicity and different dietary structure in different cultures may influence this process.

Obviously, the observation period of the present study is too short for any change of risk profile. The marginal change of systolic BP and of triglyceride would be considered irrelevant. In contrast, Japanese studies suggested that shift work is an independent risk factor for the onset of hypertension (24-28) and adversely affected lipid metabolism (29). Several other limitations of the present study have to be mentioned. The change in lipids and glucose are subjects of the study, instead of dietary habits and energy intake, so that the relationship between nutrition pattern and shift work cannot be answered.

Healthy worker effect in general, here specifically healthy shift worker effect, is firstly considered to be a primary selection process at entry into employment. Systematic selection based on the risk profiles in favor of shift workers is not present in our study. Self-selection, which was suggested in a Swedish study (30) however, cannot be excluded at the choice of occupational training in the present study. Some kinds of professional training, eg, chemical workers, are more likely to be assigned to shift work. As shown by the Million Women Study (9), women from a lower socioeconomic status (SES) were more prevalent in shift work. One may explain that those from a lower SES were more willing to take on activities involved in shift working time because of monetary incentives. Healthy worker effect is therefore sometimes considered to be a selection of workforce rather than a selection into a workforce (31). Those trainees whose future job assignment were unknown were excluded from the analyses. The reasons for unknown job assignment could be either no termination of training, unemployment, or joining the affiliated company and contractors, while the last may represent the majority. The selection bias resulting from all these reasons should not be counted as a healthy shift worker effect. We examined the differences between those who started their job activities in shift or day working time. The potential selection due to the first two reasons may contribute to a general healthy worker effect, comparing employed with the unemployed. An additional reason for exclusion of the trainees who joined the affiliated companies is that the shift schedule is probably different from the studied $4 \times 12$ system. The exclusion of this part of the study population will limit the generalizability of our findings. The fact that only the trainees who decided on technical professional training were included in the study warranted to some extent comparable education, occupational status, and, within a company, comparable income as well. An internal comparison poses another advantage that some other factors associated with employment, such as better access to healthcare, regular disease screening, and higher living standard which is beneficial for health effect $(32,33)$, may limit the extent of the healthy worker effect.

A potential "select in" for entry into the company would raise a selection bias in comparison to the general population, rather than a healthy shift worker effect. This source of bias depends partially on the regional availability for a job and the economic situation in general. A potential selection resulting from the employer's decision is of minor concern because no specific disease is per se considered to preclude persons from performing shift work. And this cohort of trainees was indeed too young to develop chronic diseases.

Secondary selection is not addressed in the present study. Firstly, the data is not properly prepared for this objective. The personnel records for any change of job activity are routinely documented for administration purposes. The reasons for change of workplace or working time are not documented in an unambitious way to address the "select out" effect. Previous research that focused on "secondary selection" showed that those people moving out of shift work job did not reveal unfavorable changes in any of the cardiovascular risk factors compared with workers who remained in shift work (13).

A major limitation of the present study is the missing measurements and drop-outs during the follow-up, which causes loss of power and possibly attrition bias. We found lower attrition rates among shift workers. The better completeness of follow-up among shift workers may have something to do with the comprehensive health surveillance and health promotion programs for shift workers in particular (34). Attrition analyses were done to check the potential relationship between working time schedule and missing values. We found that those who reported $>2$ drinks per week at baseline were more likely to drop-out of the follow-up examination, both among future day and shift workers. In addition, active smoking at baseline was 
associated with attrition at the time of employment. That unfavorable health behavior is linked with higher likelihood of attrition, is in line with the findings of the previous literature (35). The authors found there was no serious bias in estimates of change and in determinants of change due to attrition, although the attrition was non-random. Furthermore, we used the data collected from the general health checks in frame of health surveillance and health promotion offered by the employer. The specific aspects related with shift work, eg, lifestyle or sleep quality, were not possible to be examined.

Several strengths of the present study are worthwhile mentioning. Firstly, a longitudinal observation of career starters makes it possible to account for and control the healthy worker effect. In the body of literature, truncated exposure history and missing start status generally hamper precise assessment of risk profiles, while this appears to be a strength of the present study in contrast. Secondly, the present study is based on an internal comparison within a company. To handle the issue of internal comparability, we restricted the study population who decided on technical training to achieve maximum comparability with respect to age, occupational risk profiles, and SES. In addition, a parallel design ensures equal length of observation, ie, employment duration, assuming that employment duration is a proxy for work-related health risks, which should mostly be comparable in both groups. In respect to change in smoking behavior, we used an approach of state transition. The advantage of this approach is that intra-individual change is taken into account, using one's own baseline information as the control. This concept of analyses was applied consistently for other continuous parameters, in which intra-individual differences were put into consideration as well.

In summary, a primary selection in favor of future shift workers is not supported by our findings. Smokers were already more prevalent among (future) shift workers before their involvement in shift working schedules. The social environment associated with shift work is in part responsible for the development of smoking behavior. Based on the fact that deteriorating cardiovascular risk profiles are a long-term process and that the shift work is in principle indispensable for an industrial society, early intervention and health education are fundamental measures to modify the progression. An ergonomic design as the studied shift system with only a single nightshift in a row might result in a limited circadian disruption (36). Furthermore, a comprehensive health promotion program in relation to prevention and health protection for shift workers and additional measures orientated towards the career starters, which has been implemented in the company since 2002 may mitigate in the long run excess risks for CVD.

\section{References}

1. Puttonen S, Härmä M, Hublin C. Shift work and cardiovascular disease - pathways from circadian stress to morbidity. Scand J Work Environ Health. 2010;36:96-108. http://dx.doi. org/10.5271/sjweh.2894.

2. Vyas M, Garg AX, Iansavichus AV, Costella J, Donner A, Laugsand LE, et al. Shift work and vascular events: systematic review and meta-analysis. BMJ. 2012;345:e4800. http:// dx.doi.org/10.1136/bmj.e4800.

3. Bøggild H, Knutsson A. Shift work, risk factors and cardiovascular disease. Scand J Work Environ Health. 1999;25:85-99. http://dx.doi.org/10.5271/sjweh.410.

4. Esquirol Y, Perret B, Ruidavets JB, Marquie JC, Dienne E, Niezborala M, Ferrieres J. Shift work and cardiovascular risk factors: new knowledge from the past decade. Arch Cardiovasc Dis. 2011;104:636-68. http://dx.doi. org/10.1016/j.acvd.2011.09.004.

5. Yong M, Nasterlack M, Pluto RP, Elmerich K, Karl D, Knauth P. Is health, measured by Work Ability Index, affected by 12hour rotating shift schedules? Chronobiol Int. 2010;27:113548. http://dx.doi.org/10.3109/07420528.2010.490111.

6. Yong M, Nasterlack M, Germann C, Lang S, Oberlinner C. Shift work and risk of non-cancer mortality in a cohort of German male chemical workers. Int Arch Occup Environ Health. 2014;87:763-73. http://dx.doi.org/10.1007/s00420013-0922-5.

7. Yong M, Nasterlack M, Messerer P, Oberlinner C, Lang S. A retrospective cohort study of shift work and risk of cancerspecific mortality in German male chemical workers. Int Arch Occup Environ Health. 2014;87:175-83. http://dx.doi. org/10.1007/s00420-013-0843-3.

8. Yong M, M Blettner, K Emrich, M Nasterlack, C Oberlinner, GP Hammer. A retrospective cohort study of shift work and risk of incident cancer among German male chemical workers. Scand J Work Environ Health. 2014;40:502-10. http://dx.doi. org/10.5271/sjweh.3438.

9. Wang XS, Travis RC, Reeves G, Green J, Allen NE, Key TJ, Roddam AW, Beral V. Characteristics of the Million Women Study participants who have and have not worked at night. Scand J Work Environ Health. 2012;38:590-9. http://dx.doi. org/10.5271/sjweh.3313.

10. Kubo T, Oyama I, Nakamura T, Shirane K, Otsuka H, Kunimoto $\mathrm{M}$, et al. Retrospective cohort study of the risk of obesity among shift workers: findings from the Industry-based Shift Workers' Health study, Japan. Occup Environ Med. 2011;68:327-31. http://dx.doi.org/10.1136/ oem.2009.054445.

11. Nabe-Nielsen, K, Garde AH, Tüchsen F, Hogh A, Diderichsen F. Cardiovascular risk factors and primary selection into shift work. Scand J Work Environ Health. 2008;34:206-12. http:// dx.doi.org/10.5271/sjweh.1230.

12. Van Amelsvoort LG, Jansen NW, Kant I. Smoking among shift workers: more than a confounding factor. 
Chronobiol Int. 2006;23:1105-13. http://dx.doi. org/10.1080/07420520601089539.

13. Van Amelsvoort LG, Schouten EG, Kok FJ. Impact of one year of shift work on cardiovascular disease risk factors. J Occup Environ Med. 2004;46:699-706. http://dx.doi. org/10.1097/01.jom.0000131794.83723.45.

14. Knutsson A, Andersson H, Berglund U. Serum lipoproteins in day and shift workers: a prospective study. Br J Ind Med. 1990;47:132-4.

15. Suwazono Y1, Dochi M, Sakata K, Okubo Y, Oishi M, Tanaka $\mathrm{K}$, et al. A longitudinal study on the effect of shift work on weight gain in male Japanese workers. Obesity. 2008;16:188793. http://dx.doi.org/10.1038/oby.2008.298.

16. Kawachi I, Colditz GA, Stampfer MJ, Willet W, Manson JE, Speizer FE, et al. Prospective study of shift work and risk of coronary heart disease in women. Circulation. 1995;92:317882. http://dx.doi.org/10.1161/01.CIR.92.11.3178.

17. Niedhammer I, Lert F, Marne MJ. Prevalence of overweight and weight gain in relation to night work in a nurses' cohort. Int J Obes Relat Metab Disord. 1996;20:625-33.

18. van Amelsvoort LG, Schouten EG, Kok FJ. Duration of shiftwork related to body mass index and waist to hip ratio. Int J Obes Relat Metab Disord. 1999;23:973-8. http://dx.doi. org/10.1038/sj.ijo.0801028.

19. Geliebter A, Gluck ME, Tanowitz M, Aronoff NJ, Zammit GK. Work-shift period and weight change. Nutrition. 2000;16:279. http://dx.doi.org/10.1016/S0899-9007(99)00228-2.

20. Parkes KR. Shift work and age as interactive predictors of body mass index among offshore workers. Scand J Work Environ Health. 2002;28:64-71. http://dx.doi.org/10.5271/ sjweh.648.

21. Suwazono Y1, Uetani M, Oishi M, Tanaka K, Morimoto H, Nakada S, Sakata K. Estimation of the benchmark duration of alternating shift work associated with increased total cholesterol levels among male Japanese workers. Scand J Work Environ Health. 2010a;36:142-9. http://dx.doi. $\operatorname{org} / 10.5271 /$ sjweh.2893.

22. Suwazono Y1, Uetani M, Oishi M, Tanaka K, Morimoto H, Sakata K. Calculation of the benchmark duration of shift work associated with the development of impaired glucose metabolism: a 14-year cohort study on 7104 male workers. Occup Environ Med. 2010b;67:532-7. http://dx.doi. org/10.1136/oem.2009.050971.

23. Tanaka K1, Sakata K, Oishi M, Morimoto H, Nakada S, Uetani $\mathrm{M}$, et al. Estimation of the benchmark duration of shiftwork associated with weight gain in male Japanese workers. Chronobiol Int. 2010;27:1895-910. http://dx.doi.org/10.310 9/07420528.2010.516045.

24. Morikawa Y, Nakagawa H, Miura K, et al. Relationship between shift work and onset of hypertension in a cohort of manual workers. Scand J Work Environ Health. 1999;25:1004. http://dx.doi.org/10.5271/sjweh.411.

25. Sakata K1, Suwazono Y, Harada H, Okubo Y, Kobayashi E, Nogawa K. The relationship between shift work and the onset of hypertension in male Japanese workers. J Occup Environ Med. 2003;45:1002-6. http://dx.doi.org/10.1097/01. jom.0000085893.98441.96.

26. Oishi M1, Suwazono Y, Sakata K, Okubo Y, Harada H, Kobayashi E, et al. A longitudinal study on the relationship between shift work and the progression of hypertension in male Japanese workers. J Hypertens. 2005;23:2173-8. http:// dx.doi.org/10.1097/01.hjh.0000189870.55914.b3.

27. Suwazono Y, Dochi M, Sakata K, Okubo Y, Oishi M, Tanaka $\mathrm{K}$, et al. Shift work is a risk factor for increased blood pressure in Japanese men: a 14-year historical cohort study. Hypertension. 2008;52(3):581-6. http://dx.doi.org/10.1161/ HYPERTENSIONAHA.108.114553.

28. Kubo T, Fujino Y, Nakamura T, Kunimoto M, Tabata H, Tsuchiya T, et al. An industry-based cohort study of the association between weight gain and hypertension risk among rotating shift workers. J Occup Environ Med. 2013;55:1041-5. http://dx.doi.org/10.1097/JOM.0b013e31829731fd.

29. Dochi M1, Suwazono Y, Sakata K, Okubo Y, Oishi M, Tanaka K, et al. Shift work is a risk factor for increased total cholesterol level: a 14-year prospective cohort study in 6886 male workers. Occup Environ Med. 2009;66:592-7. http:// dx.doi.org/10.1136/oem.2008.042176.

30. KnutssonA,Akerstedt T. The healthy-worker effect: Self-selection among Swedish shift workers. Work \& Stress. 1992;6:163-7. http://dx.doi.org/10.1080/02678379208260350.

31. Wilcosky T, Wing S. The healthy worker effect. Selection of workers and work forces. Scand J Work Environ Health. 1987;13:70-2. http://dx.doi.org/10.5271/sjweh.2078.

32. Choi BC. Definition, sources, magnitude, effect modifiers, and strategies of reduction of the healthy worker effect. J Occup Med. 1992;34:979-88.

33. Arrighi HM, Hertz-Picciotto I. Definitions, sources, magnitude, effect modifiers, and strategies of reduction of the healthy worker effect. J Occup Med. 1993;35:890-2. http:// dx.doi.org/10.1097/00043764-199309000-00009.

34. Ott MG, Yong M, Zober A, Nasterlack M, Messerer P, Pluto R-P, et al. Impact of an occupational health promotion program on subsequent illness and mortality experience. Int Arch Occup Environ Health. 2010;83:887-94. http://dx.doi.org/10.1007/ s00420-010-0521-7.

35. Garcia M, Fernandez E, Schiaffino A, Borrell C, Marti M, Borras JM; Chis.Fu Study Group. Attrition in a populationbased cohort eight years after baseline interview: The Cornella Health Interview Survey Follow-up (CHIS.FU) Study. Ann Epidemiol. 2005;15:98-104. http://dx.doi.org/10.1016/j. annepidem.2004.06.002.

36. Leichtfried V, Putzer G, Perkhofer D, Schobersberger W, Benzer A. Circadian melatonin profiles during single 24-h shifts in anesthetists. Sleep Breath. 2011;15:503-12. http:// dx.doi.org/10.1007/s11325-010-0371-2.

Received for publication: 4 August 2014 